\title{
Air temperature was associated with ambulance transports in Osaka area, Japan
} \author{
Akira Yoshioka², Tomohiro Hirao ${ }^{2}$ \\ ${ }^{1}$ Department of Hygiene, Faculty of Medicine, Kagawa University, Kagawa, Japan; \\ *Corresponding Author: miyarin@med.kagawa-u.ac.jp \\ ${ }^{2}$ Department of Public Health, Faculty of Medicine, Kagawa University, Kagawa, Japan.
}

Nobuyuki Miyatake ${ }^{1 *}$, Noriko Sakano ${ }^{1}$, Shoko Murakami $^{1}$, Takeshi Suzue $^{2}$, Takeshi Yoda $^{2}$,

Received 4 July 2011; revised 1 August 2011; accepted 9 August 2011.

\begin{abstract}
We investigated the link between ambulance transports and meteorological parameters of summer by using daily data in Osaka area, Japan. Daily observations for ambulance transports (from July 1 to September 30, 2009) were obtained from Fire Department Service in Osaka. Data of meteorological parameters in Osaka area, Japan (from July 1 to September 30, 2009) were also obtained from Japan Meteorological Agency. Effect of meteorological parameters on ambulance transports was analyzed. A total of 49,526 ambulance transports were observed from July 1 to September 30, 2009 in Osaka, Japan. Ambulance transports were significantly correlated with mean air temperature $(r=0.298)$, the highest air temperature $(r=0.347)$, the lowest air temperature $(r=0.209)$ and daylight hours $(r=0.301)$. The higher air temperature was associated with higher ambulance transports of summer in Osaka area, Japan.
\end{abstract}

Keywords: Ambulance Transports;

Air Temperature; Osaka Area; Daylight Hours

\section{INTRODUCTION}

Global warming has become public health challenge in Japan. Global average temperatures are predicted to increase between $1.4^{\circ} \mathrm{C}$ and $5.8^{\circ} \mathrm{C}$ by the end of this century [1]. We have previously showed that estimated changes in mean temperature was $1.6^{\circ} \mathrm{C}$ for 50 years in Osaka areas, Japan [2]. In addition, by using monthly data, higher air temperature was associated with ambulance transports in Takamatsu [3] and Okayama [4] areas, Japan. Basu et al. also reported that the relation between elevated ambient air temperature and mortality in their review [5]. However, the link between ambulance transports by using daily data and meteorological parameters i.e. air temperature, humidity, atmospheric pressure and daylight hours still remains to be investigated.

Therefore, we investigated the relationship between ambulance transports of summer and meteorological parameters by using daily data in Osaka area, Japan.

\section{METHODS}

\subsection{Study Area}

Osaka area is the second largest metropolitan area in Japan and its population is about 8.7 million. Osaka city (2.6 million population, $220 \mathrm{~km}^{2}$ ) is located in the center of the metropolitan area, and have been mostly urbanized for a long time in Japan. The Osaka plain is surrounded by Hokusetsu and Rokko mountains to the north, Ikoma mountain on the east side, Izumi Mountain in the south, and Osaka Bay to the west.

\subsection{Ambulance Data}

Daily incidence data of ambulance transports was obtained from Fire Department Service in Osaka from July 1 to September 30, 2009 [6].

\subsection{Meteorological Parameters}

Daily meteorological parameters in Osaka areas in Japan for the required periods were obtained from Japan Meteorological Agency [7]. The observation spots were located at the central in the area. Daily meteorological parameters i.e. mean atmospheric pressure (land surface) $(\mathrm{hPa})$, mean atmospheric pressure (sea surface) $(\mathrm{hPa})$, total precipitation $(\mathrm{mm})$, mean air temperature $\left({ }^{\circ} \mathrm{C}\right)$, the highest air temperature $\left({ }^{\circ} \mathrm{C}\right)$, the lowest air temperature $\left({ }^{\circ} \mathrm{C}\right)$, mean humidity (\%), the lowest humidity (\%), mean velocity of the wind $(\mathrm{m} / \mathrm{s})$ and daylight hours (hours) 
were used for analysis.

\subsection{Statistical Analysis}

Simple correlation analysis was used to test the significance of the linear relationship among continuous variables. $p<0.05$ was considered to be statistically significant.

\section{RESULTS}

Profiles of used daily data in Osaka area from July 1 to September 30, 2009 were summarized in Table 1. A total of 49,526 ambulance transports were observed from July 1 to September 30, 2009 in Osaka area, Japan. Mean ambulance transports was $538.3 \pm 33.0$ /day, respectively.

We investigated the relationship between ambulance transports and meteorological parameters by simple correlation analysis (Table 2). Ambulance transports were significantly correlated with mean air temperature, the highest air temperature (Figure 1), the lowest air temperature and daylight hours. Correlation coefficient rate

Table 1. Profiles of used daily data in Osaka area from July 1 to September 30, 2009.

\begin{tabular}{lccc}
\hline & Mean \pm SD & Minimum & Maximum \\
\hline Number of days & 92 & & \\
Mean atmospheric pressure (land surface) $(\mathrm{hPa})$ & $1000.2 \pm 4.3$ & 990.0 & 1010.2 \\
Mean atmospheric pressure (sea surface) $(\mathrm{hPa})$ & $1009.6 \pm 4.4$ & 999.3 & 1019.9 \\
Total precipitation $(\mathrm{mm})$ & $2.8 \pm 5.9$ & 0.0 & 30.5 \\
Mean air temperature $\left({ }^{\circ} \mathrm{C}\right)$ & $26.6 \pm 2.3$ & 20.8 & 30.8 \\
The highest air temperature $\left({ }^{\circ} \mathrm{C}\right)$ & $31.1 \pm 2.8$ & 22.0 & 36.3 \\
The lowest air temperature $\left({ }^{\circ} \mathrm{C}\right)$ & $23.3 \pm 2.5$ & 17.8 & 27.7 \\
Mean humidity $(\%)$ & $65.4 \pm 9.2$ & 48.0 & 88.0 \\
The lowest humidity $(\%)$ & $47.7 \pm 11.4$ & 27.0 & 81.0 \\
Mean velocity of the wind $(\mathrm{m} / \mathrm{s})$ & $2.4 \pm 0.6$ & 1.4 & 4.7 \\
Daylight hours (hours) & $5.6 \pm 3.9$ & 0.0 & 12.3 \\
Ambulance transport (number/day) & $538.3 \pm 33.0$ & 454.0 & 616.0 \\
\hline
\end{tabular}

Table 2. Simple correlation analysis between ambulance transports and meteorological parameters from July 1 to September 30, 2009.

\begin{tabular}{lcc}
\hline & $r$ & $p$ \\
\hline Mean atmospheric pressure (land surface) $(\mathrm{hPa})$ & 0.086 & 0.4165 \\
Mean atmospheric pressure (sea surface) $(\mathrm{hPa})$ & 0.090 & 0.3927 \\
Total precipitation $(\mathrm{mm})$ & -0.085 & 0.4186 \\
Mean air temperature $\left({ }^{\circ} \mathrm{C}\right)$ & 0.298 & $\mathbf{0 . 0 0 3 9}$ \\
The highest air temperature $\left({ }^{\circ} \mathrm{C}\right)$ & 0.347 & $\mathbf{0 . 0 0 0 7}$ \\
The lowest air temperature $\left({ }^{\circ} \mathrm{C}\right)$ & 0.209 & $\mathbf{0 . 0 4 6 1}$ \\
Mean humidity $(\%)$ & -0.076 & 0.4694 \\
The lowest humidity $(\%)$ & -0.161 & 0.1250 \\
Mean velocity of the wind $(\mathrm{m} / \mathrm{s})$ & 0.152 & 0.1480 \\
Daylight hours (hours) & 0.301 & $\mathbf{0 . 0 0 3 5}$ \\
\hline
\end{tabular}




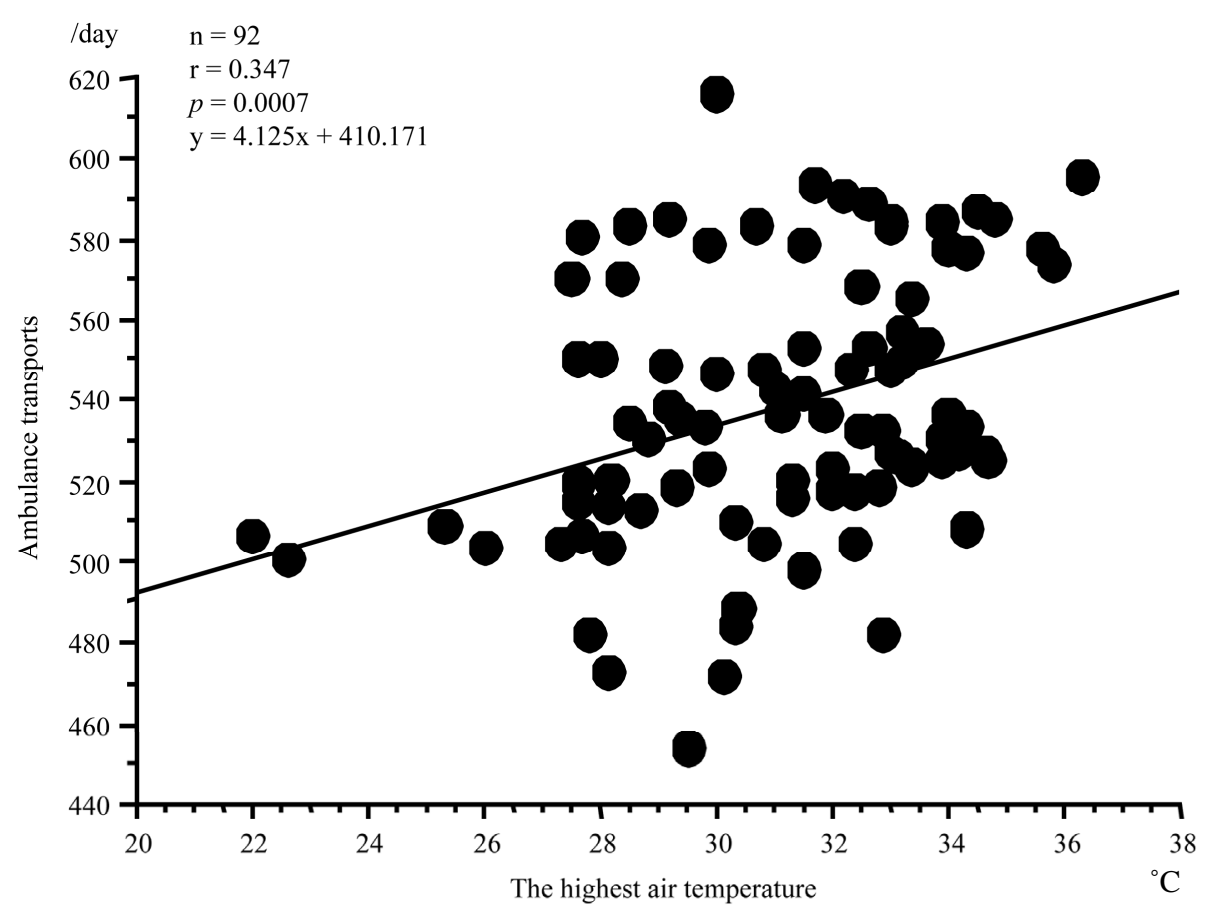

Figure 1. Simple correlation analysis between ambulance transports (/day) and the highest air temperature $\left({ }^{\circ} \mathrm{C}\right.$ ) by using daily data in Osaka area, Japan.

between the highest air temperature and ambulance transports was the highest. However, other parameters were not correlated with ambulance transports.

\section{DISCUSSION}

We firstly evaluated the link between ambulance transports and meteorological parameters by using daily data in Osaka area, Japan. The highest air temperature was closely associated with ambulance transports.

Average subsurface temperature profiles in four Asian cities (Tokyo, Osaka, Seoul and Bangkok) were compared and analyzed to evaluate the effects of surface warming [8]. The magnitude of surface warming was the largest in Tokyo $\left(2.8^{\circ} \mathrm{C}\right)$, followed by Seoul, Osaka and Bangkok. The combination of the heat island effect due to urbanization and global warming on subsurface temperatures also relates to global ground water quality issues [9]. In addition, in some literatures, the link between high temperatures and heat-related diseases has been reported. Bai et al. reported that the number of unusual deaths in the summer of 1994 in Osaka, Japan was more compared to those of previous years [10]. Nakai et al. also investigated heat-related deaths in Japan from 1968 through 1994 and heat-related deaths were most prone to occur on days with a peak daily temperature above 38 degrees $C$ [11]. They reported that incidence of heat-related deaths showed and exponential dependence on the number of hot days [11]. Qiu et al. reported that an unusually hot spell in 1999 was followed by a high mortality rate in Hokkaido, Japan [12]. Piver et al. showed that heat stroke was associated with prolonged exposures to higher air temperatures that usually occur in the summer months of July and August in 1980-1995 in Tokyo [13]. In our previous study, higher air temperature was closely associated with higher ambulance transports in Takamatsu and Okayama city using monthly data $[3,4]$. We also found that high air temperature was associated with ambulance transports by using daily data in Osaka area, Japan in this study. Coefficient rate between ambulance transports and the highest air temperature was the highest among parameters. Furthermore, the slope of the regression line (change in highest air temperature vs change in ambulance transports) in Osaka city was 4.125 (Figure 1). Accordingly, we found that a $1^{\circ} \mathrm{C}$ increase in highest air temperature of summer in Osaka area, Japan, corresponded to a 4.125/day increase in ambulance transports in Osaka area, Japan.

Potential limitations still remain in this study. First, the link between ambulance transports and air temperatures, which was noted in this study, may not apply for the link among individuals. Second, we could not directly evaluate heat-related diseases or deaths. Therefore, we could not accurately evaluate the link between ambulance transports and high air temperatures. Further studies are required to prove such link. 


\section{ACKNOWLEDGEMENTS}

This research was supported in part by Research Grants from FUKUTAKE Science \& Culture Foundation, Japan.

\section{REFERENCES}

[1] Intergovernmental Panel on Climate Change (2001) The scientific basis: Contribution of working group 1 to the Third assessment report. Cambridge University Press, Cambridge, 1-944.

[2] Miyatake, N., Sakano, N., Murakami, S., Suna, S., Suzue, T. and Hirao, T. (2011) Comparison of the temperatures among rural, urban and metropolitan areas around the Inland Sea in Japan. Environmental Monitoring and Assessment, 181, 525-530.

[3] Miyatake, N., Nakao, M., Sakano, N., Suna, S., Suzue, T. and Hirao, T. (2011) Higher ambulance transports were closely associated with higher ambulance transports in Takamatsu area, Japan. Journal of Environmental Protection, 2, 72-75. doi:10.4236/jep.2011.21007

[4] Sakano, N., Miyatake, N., Suzue, T., Suna, S., Hirao, T. and Ogino, K. (2011) The relation between high temperatures and ambulance transports in Okayama city, Japan (in Japanese). Journal of Preventive Medicine, 6, 17-20.

[5] Basu, R. and Samet, J.M. (2002) Relation between elevated ambient temperature and mortality: A review of the epidemiologic evidence. Epidemiologic Reviews, 24, 190-202. doi:10.1093/epirev/mxf007

[6] Fire Department Service in Osaka, Japan (2011) http://www.city.osaka.lg.jp/shobo/cmsfiles/contents/0000 093/93833/P45.pdf
[7] Japan Meteorological Agency (2011) http://www.data.jma.go.jp/obd/stats/etrn/index.php?prec no=62\&prec ch=\%91\%E5\%8D\%E3\%95\%7B\&block n o=47772\&block ch=\%91\%E5\%8D\%E3\&year=\&month $=\&$ day $=$ \&view $=$

[8] Taniguchi, M., Umemura, T. and Jago-on., K. (2007) Combined effects of urbanization and global warming on subsurface temperature in four Asian cities. Vadose Zone Journal, 6, 591-596. doi:10.2136/vzj2006.0094

[9] Knorr, W., Prentice, I.C., House, J.I. and Holland, E.A. (2005) Long-term sensitivity of soil carbon turnover to warming. Nature, 433, 298-301. doi:10.1038/nature03226

[10] Bai, H., Islam, M.N., Kuroki, H., Honda, K. and Wakasugi, C. (1995) Deaths due to heat waves during the summer of 1994 in Osaka Prefecture, Japan. Nihon Hoigaku Zasshi, 49, 265-274.

[11] Nakai, S., Itoh, T. and Morimoto, T. (1999) Deaths from heat-stroke in Japan: 1968-1994. International Journal of Biometeorology, 43, 124-127. doi:10.1007/s004840050127

[12] Qiu, D., Tanihata, T., Aoyama, H., Fujita, T., Inaba, Y. and Minowa, M. (1999) Relationship between a high mortality rate and extreme heat during the summer of 1999 in Hokkaido Prefecture, Japan. Journal of Epidemiology, 12, 254-257.

[13] Piver, W.T., Ando, M., Ye, F. and Portier, C.J. (1999) Temperature and air pollution as risk factors for heat stroke in Tokyo, July and August 1980-1995. Environmental Health Perspectives, 107, 911-916. doi:10.1289/ehp.99107911 